\title{
Albumin excretion and vascular deaths in NIDDM
}

\author{
J.M.MacLeod, J.Lutale, S.M. Marshall \\ Department of Medicine, University of Newcastle upon Tyne, Newcastle upon Tyne, UK
}

Summary Non-insulin-dependent diabetes mellitus (NIDDM) is associated with premature mortality, generally thought to be exaggerated in patients with microalbuminuria. This prospective 8-year follow-up study aimed to determine outcome, mortality and cause of death in NIDDM patients with abnormal urinary albumin excretion compared to those with normal albumin excretion. We recruited 153 NIDDM patients with abnormal urinary albumin excretion and 153 control subjects with albumin excretion within the normal non-diabetic range, matched for age, sex and duration of diabetes, from three University hospital diabetic clinics in Newcastle upon Tyne. The outcome measures were status at follow-up, mortality and cause of death. Subjects with abnormal albumin excretion had a significantly higher 8-year mortality than matched control subjects (Odds Ratio $1.47, p=0.02$; 108 vs 66 per 1000 person years follow-up, $p<0.001$ ). This difference was seen at all levels of abnormal albumin excretion, from just out- side the normal range $(10.6-29.9 \mu \mathrm{g} / \mathrm{min}: 104$ vs 61 per 1000 person years follow-up, $p<0.001$ ) to more conventional definitions of microalbuminuria $(\geqslant 30 \mu \mathrm{g} / \mathrm{min}: 111$ vs 71 per 1000 person years follow-up, $p<0.01$ ). Those with abnormal albumin excretion had an excess of vascular deaths compared to matched control subjects (Odds Ratio 1.70, $p=$ 0.009 ), again at different levels of albumin excretion $(10.6-29.9 \mu \mathrm{g} / \mathrm{min} p<0.01,30-150 \mu \mathrm{g} / \mathrm{min} p<0.05)$. On multivariate analysis, age, initial ischaemic heart disease and initial albumin excretion rates were independent predictors of death from all causes. Even a minor elevation of albumin excretion above the normal non-diabetic range is associated with excess mortality from vascular causes in NIDDM. [Diabetologia (1995) 38: 610-616]

Key words Non-insulin-dependent diabetes mellitus, albumin excretion, microalbuminuria, causes of death, cardiovascular mortality.
It is widely accepted that non-insulin-dependent diabetes mellitus (NIDDM) carries an increased risk of premature mortality. A number of studies over the last decade have suggested that the excess mortality

Received: 6 May 1994 and in final revised form: 16 November 1994

Corresponding author: Dr. J.M.MacLeod, Department of Medicine, University of Newcastle upon Tyne, The Medical School, Framlington Place, Newcastle upon Tyne NE2 4HH, UK

Abbreviations: NIDDM, Non-insulin-dependent diabetes mellitus; AER, albumin excretion rate; SBP, systolic blood pressure; DBP, diastolic blood pressure; $\mathrm{CI}$, confidence interval; MAP, mean arterial pressure. is particularly high in diabetic patients with raised urinary albumin excretion rates (AER), so-called microalbuminuria [1-5]. Using timed, overnight urine collections, Jarrett et al. [2] demonstrated that NIDDM patients with albumin excretion rates greater than $30 \mu \mathrm{g} / \mathrm{min}$ were at increased risk of early death, but the excess risk apparently extended down to rates as low as $10 \mu \mathrm{g} / \mathrm{min}$. Mogensen [1] showed an increasing risk of mortality in NIDDM with rising urinary albumin concentrations measured in early morning urine samples; from a $37 \%$ increase above mortality rates in the non-diabetic population at albumin concentrations below $15 \mu \mathrm{g} / \mathrm{ml}$ to a $148 \%$ rise at 30-140 $\mu \mathrm{g} / \mathrm{ml}$. Mattock and colleagues [4] showed an excess mortality in a prospective study of micro- 
albuminuria in NIDDM using the consensus definitions developed for use in IDDM, 20-200 $\mu \mathrm{g} / \mathrm{min}$ [6]. In non-diabetic subjects a similar relationship has been shown, with an AER greater than $7.5 \mu \mathrm{g} / \mathrm{min}$ being associated with a threefold increase in the number of deaths when compared to an AER lower than $7.5 \mu \mathrm{g} / \mathrm{min}$ [7] and $33 \%$ of microalbuminuric subjects dying during follow-up compared to $2 \%$ of subjects with AER less than $20 \mu \mathrm{g} / \mathrm{min}$ in the Islington Diabetes Survey [8]. Thus, although the risk of early death increases with urinary albumin excretion, the level of AER at which the excess risk of mortality in NIDDM becomes significant has not been firmly established.

Many European studies of NIDDM have shown that deaths were predominantly due to cardiovascular disease [2-5, 9-14]. Further, the presence of microalbuminuria in NIDDM was found to be predictive of all causes of mortality [1-5]. It was widely inferred from these latter studies that microalbuminuria per se confers an increased risk of early vascular death in NIDDM, but this assumption has not been sufficiently tested. Most of the studies were retrospective: one prospective study had only 14 deaths in all over a period of 4 years, but found that the majority of deaths, mainly vascular, were in the microalbuminuric group [4]. None has compared outcome and causes of death in matched subjects with and without raised albumin excretion. In order to address this question, we have compared the mortality rates and causes of death in NIDDM patients with abnormal AER with a group of matched patients with normal AER in an 8-year prospective study.

\section{Patients and methods}

Ethical approval for the study was obtained from Newcastle Health Authority and University of Newcastle Joint Ethics Committee. Patients gave informed, written consent before entering the study. The diagnosis of diabetes was made on the basis of an oral glucose tolerance test or two blood glucose levels as defined by World Health Organisation criteria [15]. NIDDM was defined as the onset of diabetes after the age of 35 years and no requirement of regular insulin therapy in the first 2 years. The four patients identified as having secondary diabetes were excluded from the study. Timed, overnight urine samples were collected from 525 unselected NIDDM patients attending the three Newcastle University hospital outpatient diabetic clinics during 1983-1984. No patient was studied within 6 months of diagnosis or 1 month of acute metabolic decompensation. Patients with urinary tract infection, as indicated by positive dipstick testing for blood, nitrites or leucocytes (Nephur Test; Boehringer Mannheim, Mannheim, Germany), were excluded. Details of age, sex, age of onset of diabetes, current treatment of diabetes and treatment of hypertension were recorded. Peripheral vascular disease was defined as a history of intermittent claudication or of vascular surgery or amputation, or the absence of foot pulses on examination. Ischaemic heart disease was defined as a history of angina pectoris or previous myocardial infarction diagnosed by at least two of the following; typical history, ECG changes or enzyme changes. Blood pressure was measured after $5 \mathrm{~min}$ sitting, using Korotkoff's phase $\mathrm{V}$ and mean arterial blood pressure calculated as diastolic pressure $+1 / 3$ (systolic pressurediastolic pressure). Blood was taken for $\mathrm{HbA}_{1}$ estimation. Each patient was given written instructions on how to perform a timed overnight urine collection for estimation of AER and asked to collect one overnight sample on the night prior to their clinic visit.

In 1992, 153 patients whose original AER was greater than the upper limit of normal (geometric mean $\times / \div 2 \mathrm{SD}$ ) for non-diabetic subjects in our laboratory, $10.5 \mu \mathrm{g} / \mathrm{min}$ [16], were matched to 153 patients with normal AER for age, known duration of diabetes and sex. In performing the matching, a margin of \pm 2 years was used for age and duration. In the event of two control subjects being available the closer match was taken. Only details of age, duration, sex and initial AER category were available at the time of matching. These factors did not differ between diabetic cases and control subjects; age $66.7 \pm 0.8$ vs $66.6 \pm 0.8$ years, (mean $\pm \mathrm{SEM}$ ), $p=0.9$; sex 86 male: 67 female each group and known duration of diabetes $8.6 \pm 0.6$ vs $8.4 \pm 0.5$ years, $p=0.8$. In order to determine the level of AER at which the excess mortality risk was conferred, the abnormal AER group was subdivided using cut-off points suggested by previous studies in NIDDM [1,2], one of which utilised the same assay as our laboratory [2]: "Borderline microalbuminuria" group, AER 10.6-29.9 $\mu \mathrm{g} / \mathrm{min}, n=74$; Microalbuminuria group, AER $30-149.9 \mu \mathrm{g} / \mathrm{min}, n=48$ and Proteinuric group, AER $\geqslant 150 \mu \mathrm{g} / \mathrm{min}, n=31$. No patient was receiving renal replacement therapy at study commencement and none required such therapy during the study. Details of age, sex and duration for these three subgroups are given in Table 1.

The status (living or dead) of all of the patients and control subjects in 1992 was determined from hospital, general practitioner and Family Health Service Authority records. Cause of death was obtained from the same sources plus local Coroners' Office records. Where the cause of death was not clear from these records, copies of death certificates were obtained from the Office of Population Census Surveys.

Laboratory methods. Urinary albumin was measured by sensitive single-antibody radio immunoassay with precipitation by polyethylene glycol 6000 [17]. The interassay coefficient of variation was $6.9 \%$ at $6 \mathrm{mg} / \mathrm{l}$ and $10.3 \%$ at $121 \mathrm{mg} / \mathrm{l}$. Glycated haemoglobin was measured by Corning electrophoresis; reference range $5.0-7.5 \%$.

\section{Statistical analysis}

Kaplan-Meier survival analysis for all cause mortality and vascular mortality was performed; Odds Ratio and log rank test results are given. Mortality rates per 1000 person years of follow-up were calculated for control subjects and cases. In order to assess whether abnormal albumin excretion conferred an excess risk of premature death, and specifically of vascular death, each case and matched control subject were analysed as a pair using McNemar's chi-square test of paired data [18]. This takes into account the matching for the possible confounding factors of age, sex and known duration of diabetes. Other statistical analyses were done using the SPSS/PC package [19]. Differences between the groups were assessed using the Student's $t$-test or chi-square test as appropriate. AER was logarithmically transformed before analysis in order to correct for the positively skewed distribution of values. Logis- 
Table 1. Details of subgroups with different levels of urinary albumin excretion

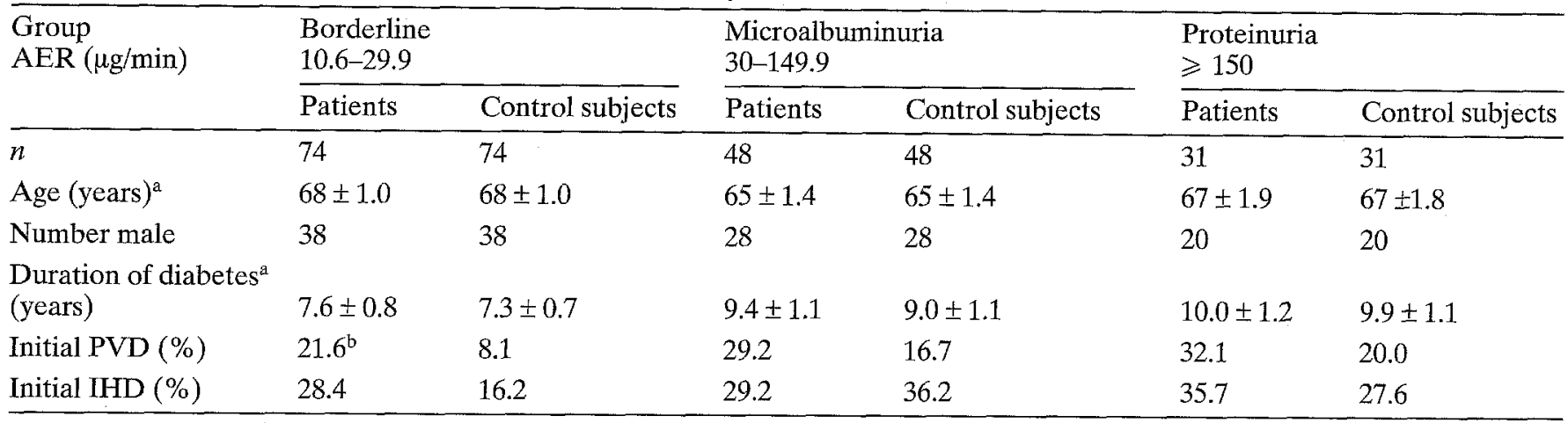

Initial PVD or IHD (\%), evidence of peripheral vascular disease or ischaemic heart disease at initial screening.

${ }^{\mathrm{a}}$ Values given as mean $\pm \mathrm{SEM} ;{ }^{\mathrm{b}} p<0.02$ vs control subjects

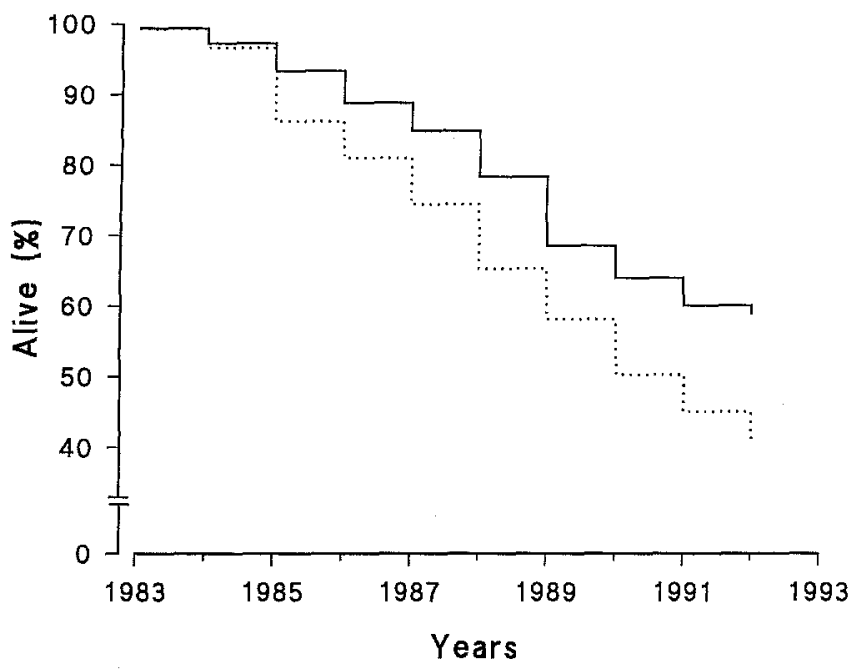

Fig. 1. Survival curves for subjects according to initial urinary albumin excretion rate; patients with abnormal AER $>10.5 \mu \mathrm{g} / \mathrm{min}$.......; control subjects with normal AER $\leq 10.5 \mu \mathrm{g} / \mathrm{min} \longrightarrow$. Log rank test $p=0.02$

tic multivariate analyses were performed using step-wise entry with status and vascular death as outcome as the dependent variables. Adjusted and unadjusted risk ratios with $95 \%$ confidence intervals are given. Results are expressed as mean \pm SEM, except for AER which is expressed as median $\times 1 \div$ tolerance factor due to the $\log$ transformation.

\section{Results}

Status. Over the period of follow-up, 90 of the 153 patients with abnormal AER died compared to 63 of the control group (Odds Ratio 1.47, $95 \%$ confidence interval (CI) $1.06-2.03, p=0.02$; log rank test $p=0.02$ ) (Fig. 1) and $\chi^{2} 10.3$, Odds Ratio $2.23,95 \%$ CI $1.32-3.87, p<0.002$ by McNemar's test). Subjects with abnormal AER had a higher mortality rate than matched control subjects (108 vs 66 per 1000 person years follow-up, $p<0.001$ ). A significant difference in mortality was also seen separately in the

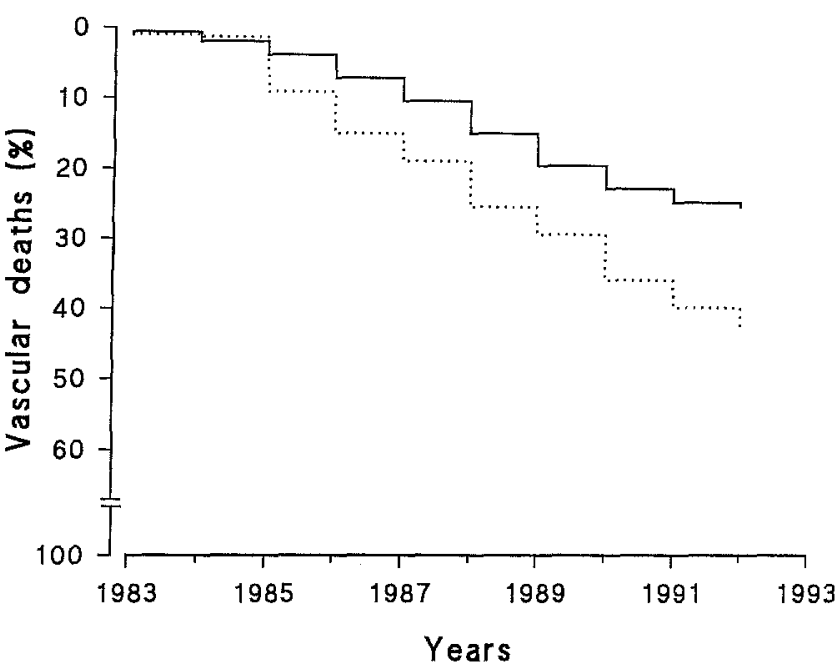

Fig. 2. Vascular death as outcome for subjects according to initial urinary albumin excretion rate; patients with abnormal AER $>10.5 \mu \mathrm{g} / \mathrm{min}$.......; control subjects with normal AER $\leq 10.5 \mu \mathrm{g} / \mathrm{min} \longrightarrow . \log$ rank test $p=0.008$

borderline group, with 43 cases dying during followup compared to 29 control subjects $\left(\chi^{2} 5.4\right.$, Odds Ratio $2.27,95 \%$ CI $1.08-5.12, p<0.05$ by McNemar's test; mortality rates 104 vs 61 per 1000 person years follow-up, $p<0.001)$ ) and in those with albumin excretion $\geqslant 30 \mu \mathrm{g} / \mathrm{min}$ (microalbuminuric and proteinuric) with 47 cases dead vs 34 control subjects, $\left(\chi^{2}\right.$ 5.1 , Odds Ratio $2.18,95 \%$ CI 1.03-4.93, $p<0.05$ by McNemar's test; mortality rates 111 vs 71 per 1000 person years follow-up, $p<0.01$ ). Early mortality rates, over the first 4 years of follow-up, were higher in subjects with abnormal AER than control subjects (99 vs 55 per 1000 person years follow-up, $p<0.01$ ) but were not significantly different from mortality rates over the 8-year period.

Cause of death. Cause of death (Table 2) was determined for all but five patients and four control subjects. Deaths due to ischaemic heart disease, periph- 
Table 2. Outcome and causes of death for all control subjects, all patients and patients in subgroups

\begin{tabular}{|c|c|c|c|c|c|}
\hline & \multicolumn{5}{|c|}{ Albumin excretion rate $(\mu \mathrm{g} / \mathrm{min})$} \\
\hline & $\leqslant 10.5$ & $>10.5$ & $10.6-29.9$ & $30-149.9$ & $\geqslant 150.0$ \\
\hline$n$ & 153 & 153 & 74 & 48 & 31 \\
\hline Dead (\%) & 41.2 & 58.8 & 58.1 & 50.0 & 74.2 \\
\hline \multicolumn{6}{|l|}{ Cause of death ${ }^{a}$} \\
\hline Ischaemic heart disease $(\%)$ & 18.9 & 32.0 & 36.5 & 25.0 & 32.2 \\
\hline Other $(\%)$ & 7.8 & 5.8 & 2.6 & 2.1 & 19.4 \\
\hline Cause unknown (\%) & 2.6 & 3.3 & 5.4 & 0.0 & 3.2 \\
\hline
\end{tabular}

${ }^{a}$ Cause of death quoted as percentage of initial cohort

Table 3. Baseline factors influencing outcome in the abnormal group

\begin{tabular}{|c|c|c|c|c|c|c|}
\hline \multirow[b]{3}{*}{ Outcome } & \multicolumn{6}{|c|}{ Albumin excretion rate $(\mu \mathrm{g} / \mathrm{min})$} \\
\hline & \multicolumn{2}{|l|}{$\geqslant 10.5$} & \multicolumn{2}{|l|}{$10.6-29.9$} & \multicolumn{2}{|l|}{$\geqslant 30$} \\
\hline & Dead & Alive & Dead & Alive & Dead & Alive \\
\hline Age (years) & $70 \pm 0.8$ & $63 \pm 1.3^{d}$ & $70 \pm 1.1$ & $65 \pm 1.6^{b}$ & $69 \pm 1.2$ & $60 \pm 1.9^{\mathrm{d}}$ \\
\hline Duration & $10.0 \pm 0.8$ & $6.5 \pm 0.7^{\mathrm{d}}$ & $8.3 \pm 1.2$ & $6.5 \pm 0.9$ & $11.8 \pm 1.1$ & $6.5 \pm 1.1^{\mathrm{d}}$ \\
\hline $\operatorname{AER}(\mu \mathrm{g} / \mathrm{min})$ & $49.4 \times 1 \div 3.9$ & $36.4 \times 1 \div 3.0$ & $15.6 \times / \div 1.3$ & $15.5 \times / \div 1.3$ & $142.5 \times l \div 2.8$ & $82.9 \times 1 \div 2.4^{b}$ \\
\hline $\mathrm{BP}_{\mathrm{x}}(\%)$ & 22.2 & 21.1 & 18.6 & 22.6 & 23.4 & 21.9 \\
\hline $\mathrm{HbA}_{1}(\%)$ & $11.1 \pm 0.4$ & $9.6 \pm 0.4^{b}$ & $11.2 \pm 0.4$ & $9.1 \pm 0.6^{c}$ & $10.9 \pm 0.6$ & $10.2 \pm 0.7$ \\
\hline Insulin $\mathrm{R}_{\mathrm{x}}(\%)$ & 28.9 & 20.6 & 27.9 & 22.6 & 29.8 & 18.9 \\
\hline Initial PVD (\%) & 34.9 & $14.3^{c}$ & 26.2 & 16.1 & 43.2 & $12.5^{\mathrm{c}}$ \\
\hline Initial IHD (\%) & 41.4 & $19.4^{\mathrm{c}}$ & 37.2 & $16.4^{\mathrm{a}}$ & 45.4 & $22.6^{\mathrm{a}}$ \\
\hline
\end{tabular}

$\mathrm{BP}_{\mathrm{x}}(\%)$, Known hypertension, treated with any class of antihypertensive agent; Insulin $\mathrm{R}_{\mathrm{x}}(\%)$, insulin treated, having previously been on oral hypoglycaemic agents; Initial PVD or
IHD (\%), evidence of peripheral vascular disease or ischaemic heart disease at initial screening. ${ }^{\mathrm{a}} p<0.05$; ${ }^{\mathrm{b}} p<0.02$; ${ }^{\mathrm{c}} p<0.005 ;{ }^{\mathrm{d}} p<0.001$ eral vascular disease and cerebrovascular disease were classed as "vascular". An excess of vascular deaths was seen in the abnormal group on survival analysis. (Odds Ratio 1.70, $95 \%$ CI 1.14-2.54, $p=$ 0.009 ; log rank test $p=0.008$ ) (Fig. 2). All of the 153 matched pairs were analysed to determine whether there existed an excess number of pairs in which the index case had died of vascular causes whilst the control had either died of non-vascular disease or was still alive at follow-up. An excess of vascular deaths was seen in the group with abnormal AER compared to their matched control subjects $\left(\chi^{2} 10.56\right.$, Odds Ratio 2.37, 95\% CI 1.36-4.29, $p<0.001$ by McNemar's test). Similar results were obtained in the borderline group vs control subjects $\left(\chi^{2} 8.0\right.$, Odds Ratio $3.00,95 \%$ CI $1.30-7.73, p<0.01)$ and the microalbuminuria group vs control subjects $\left(\chi^{2}\right.$ 3.9 , Odds Ratio $2.50,95 \%$ CI $0.92-7.86, p<0.05)$. In the smaller proteinuric group, the excess of vascular deaths approached significance $\left(\chi^{2} 3.8\right.$, Odds Ratio $1.2,95 \% \mathrm{CI} 0.30-4.97, p=0.06)$. No significant difference was seen between the abnormal group and control subjects in deaths due to malignancy. Periph- eral vascular disease was the primary cause of death for six patients: two normoalbuminuric, two from the borderline group and two microalbuminuric. Renal failure was the certified primary cause of death for only one patient who had a baseline AER of $213 \mu \mathrm{g} /$ min.

Initial vascular disease, blood pressure and albumin excretion. Subjects with abnormal AER had a higher initial prevalence of clinically evident large vessel disease than matched control subjects $(49.6 \%$ vs $29.6 \%$, $p<0.001)$ and higher mean arterial blood pressure (MAP $110 \pm 1$ vs $103 \pm 1 \mathrm{~mm} \mathrm{Hg}, p<0.001$ ). Similarly, vascular disease was more prevalent, and blood pressure higher in the subgroup of borderline cases than their matched control subjects $(41.1 \%$ vs $21.6 \%, p=0.01$; MAP $109 \pm 2$ vs $102 \pm 2 \mathrm{~mm} \mathrm{Hg}$, $p<0.01)$ and in those with AER greater than $30 \mu \mathrm{g} /$ $\min (57.3 \%$ vs $37.7 \%, p<0.02$; MAP $111 \pm 2$ vs $104 \pm 2 \mathrm{~mm} \mathrm{Hg}, p=0.005)$.

Baseline factors and outcome. Within the entire abnormal group, those who died during the follow-up 
Table 4. Baseline factors influencing outcome: all survivors vs all deaths

\begin{tabular}{llll}
\hline Outcome & All alive & $\begin{array}{l}\text { Vascular } \\
\text { deaths }\end{array}$ & $\begin{array}{l}\text { Other } \\
\text { deaths }\end{array}$ \\
\hline$n$ & 153 & 104 & 49 \\
Age (years) & $63 \pm 0.8$ & $70 \pm 0.8^{\mathrm{c}}$ & $71.9 \pm 1.1^{\mathrm{d}}$ \\
Duration & $7.3 \pm 0.5$ & $10.2 \pm 0.7^{\mathrm{c}}$ & $8.4 \pm 1.0$ \\
$\mathrm{AER}(\mu \mathrm{g} / \mathrm{min})$ & $9.3 \times / \div 1.2$ & $19.4 \times / \div 4.5^{\mathrm{c}} 18.7 \times / \div 5.6^{\mathrm{b}}$ \\
$\mathrm{SBP}(\mathrm{mm} \mathrm{Hg})$ & $152 \pm 2$ & $155 \pm 3$ & $153 \pm 4$ \\
$\mathrm{DBP}(\mathrm{mm} \mathrm{Hg})$ & $85 \pm 1$ & $83 \pm 1$ & $82 \pm 2$ \\
$\mathrm{BP} \mathrm{R}_{\mathrm{x}}(\%)$ & 19.6 & 18.3 & 18.8 \\
$\mathrm{Hb} \mathrm{A}_{1}(\%)$ & $9.6 \pm 0.3$ & $10.5 \pm 0.4$ & 10.4 \\
Insulin $\mathrm{R}_{\mathrm{x}}(\%)$ & 22.8 & 31.7 & 26.5 \\
$\begin{array}{l}\text { Initial peripheral } \\
\text { vascular disease }(\%)\end{array}$ & 13.1 & $29.1^{\mathrm{c}}$ & 20.0 \\
$\begin{array}{l}\text { Initial ischaemic } \\
\text { heart disease }(\%)\end{array}$ & 15.8 & $40.2^{\mathrm{c}}$ & $36.9^{\mathrm{d}}$ \\
\hline
\end{tabular}

$\mathrm{BP}_{\mathrm{x}}(\%)$, Known hypertension, treated with any class of antihypertensive agent; Insulin $\mathrm{R}_{\mathrm{x}}(\%)$, insulin treated, having previously been on oral hypoglycaemic agents; Initial PVD or IHD (\%), evidence of peripheral vascular disease or ischaemic heart disease at initial screening. ${ }^{a} p<0.05 ;{ }^{b} p<0.02$; ${ }^{\mathrm{c}} p<0.005 ;{ }^{\mathrm{d}} p<0.001$ compared to survivors

Table 5. Regression analysis: Risk Ratios with $95 \%$ confidence intervals

\begin{tabular}{lll}
\hline $\begin{array}{l}\text { Status as dependent } \\
\text { variable }\end{array}$ & Univariate & Multivariate \\
\hline AER of $5 \mu \mathrm{g} / \mathrm{min}$ & $1.7(1.3-2.2)$ & $2.8(1.7-4.7)$ \\
AER of $15 \mu \mathrm{g} / \mathrm{min}$ & $2.5(1.6-3.8)$ & $5.7(2.4-13.7)$ \\
AER of $20 \mu \mathrm{g} / \mathrm{min}$ & $2.7(1.7-4.4)$ & $6.8(2.6-18.1)$ \\
AER of $30 \mu \mathrm{g} / \mathrm{min}$ & $3.1(1.8-5.4)$ & $8.8(2.9-26.8)$ \\
Age, per 10 years' increase & $2.8(2.0-3.8)$ & $3.4(1.9-6.0)$ \\
$\begin{array}{l}\text { Ischaemic heart disease, } \\
\text { presence of }\end{array}$ & $1.4(1.2-1.6)$ & $1.4(1.1-1.8)$ \\
\hline
\end{tabular}

period were older, with a longer known duration of diabetes, higher prevalence of large vessel disease and higher $\mathrm{HbA}_{1}$ values, than those who survived (Table 3 ). In the borderline microalbuminuria subgroup, those who died were older with higher $\mathrm{HbA}_{1}$ and more initial ischaemic heart disease while in the group with AER greater than $30 \mu \mathrm{g} / \mathrm{min}$, those who died were older, with a longer duration of diabetes, higher initial AER and more initial ischaemic heart disease and peripheral vascular disease. Blood pressure levels, use of anti-hypertensive drugs and treatment with insulin did not differ between those who died and survivors in the whole group or subgroups (Table 4). Those who died from vascular causes were older, with longer known duration of diabetes, higher prevalence of large vessel disease and higher initial AER than survivors. Subjects with abnormal
AER who died within 4 years had higher initial ischaemic heart disease and peripheral vascular disease than subjects surviving 4 years (ischaemic heart disease 48.0 vs $24.2 \%, p<0.005$; peripheral vascular disease 40.8 vs $19.0 \%, p<0.005$ ).

Multivariate analysis. Multivariate analysis of factors influencing outcome showed age, initial presence of ischaemic heart disease and initial AER to be independent determinants of death from all causes (Table 5). There was a progressive rise in risk ratio with increasing AER from within the normal range.

\section{Discussion}

Non-insulin-dependent diabetes is known to be associated with increased risk of early death with mortality rates being similar for both sexes $[1-5,7,9-14$, $20]$. This was demonstrated in our large, mainly urban cohort, with half of the 306 patients included dying over an 8-year period. Uncontrolled studies have indicated that abnormal AER may signify further, additional risk $[1-5,20]$. This large, prospective study clearly demonstrates that an excess risk of early mortality is found in NIDDM patients with raised AER when compared to patients of similar age and known duration of diabetes whose albumin excretion is within the normal range. Debate persists as to which level of albuminuria should be accepted as conferring additional risk of early mortality in NIDDM. Cut-off levels of albuminuria originally found to be predictive of the risk of developing nephropathy in insulin-dependent diabetes have been applied previously $[1-5,20]$. However, studies by Mogensen [1] and Jarrett et al. [2] suggested that the excess risk may be present at very low levels of urinary albumin excretion. The data presented here establish that this further risk does indeed extend down below the classic "microalbuminuric" range, to within the reference range for non-diabetic subjects (less than $10.5 \mu \mathrm{g} / \mathrm{min})$. By the time the AER has risen to "borderline" levels $(10.6-29.9 \mu \mathrm{g} / \mathrm{min})$ a significant excess of deaths is seen over matched control subjects with AER in the reference range.

Consideration of the causes of death in patients with abnormal AER clearly shows an excess of vascular deaths over control subjects, with over $70 \%$ of deaths in patients with abnormal AER being due to large vessel disease and over $50 \%$ to ischaemic heart disease. This current study provides firm evidence for the inference drawn from former research that the premature deaths in NIDDM patients with $a b-$ normal albumin excretion were mainly due to vascular disease and supplements the information gained from previous studies $[2-5,12,20]$.

Studies in non-diabetic and NIDDM patients have shown a link between the presence of cardiovascular 
disease and raised AER but have not demonstrated causation $[8,21-23]$. Patients in this current study with raised AER had significantly higher rates of clinically evident vascular disease than control subjects even at the lower excretion rates of 10.6$29.9 \mu \mathrm{g} / \mathrm{min}$. Baseline ECGs were not performed in this study and in using historical rather than ECG definitions of heart disease, the true prevalence of ischaemic heart disease is likely to have been underestimated [22]. Notwithstanding this, the borderline group in our study had a significant excess of vascular disease compared to control subjects, suggesting that vascular disease is already well established by the time the AER rises above normal levels. At each level of abnormal AER, those who died had a higher initial prevalence of vascular complications than survivors. Similar results were described in a cohort of patients in general practice [20]. The high prevalence of clinically evident vascular disease in those who later died is in keeping with a possible predictive value, as is suggested by the multivariate analysis, where age and the presence of vascular disease are predictive of outcome in addition to the AER. From this data it appears that a steady progression of increasing risk occurs as the AER rises, advancing through the normal range towards proteinuric levels. A threshhold of risk at an arbitrarily defined upper limit of normal AER, by whatever definition used, would be improbable.

Only one patient from the abnormal group in our study died from renal failure, compared to $3 \%$ of deaths due to uraemia in a Danish cohort [3]. In a study of 510 NIDDM patients Fabre et al. [9] found one death out of a total of 122 to be due to a combination of proliferative glomerulonephritis and diabetic nephropathy. All but one of the patients in our study were of European origin, which may partly account for the low incidence of renal deaths. The high incidence of NIDDM in patients of Asian origin and the increased incidence of end-stage renal disease in Asian patients with diabetes would tend to result in a higher percentage of renal deaths in areas with ethnically mixed populations [24]. Interestingly, among Japanese and Pima Indians, NIDDM is associated with much higher rates of death due to renal failure $[25,26]$. We found no excess of deaths due to malignancy in subjects with abnormal AER, in contrast to suggestions from previous studies of microalbuminuric patients $[5,7]$.

The effect of glycaemic control on outcome is difficult to assess from this data. Previous studies have used various assessments of glycaemic control with conflicting results. In the Danish study albumin excretion, but not mortality, was significantly related to the initial fasting glucose [3]. Mattock et al. [4] found neither $\mathrm{HbA}_{1}$ nor plasma glucose to be significant predictors of mortality. Use of insulin rather than hypoglycaemic agents or diet alone was not associat- ed with an adverse effect on outcome in the current study, in contrast to the findings of a Japanese study [25]. It remains to be seen, from long-term studies which are nearing completion, whether improved glycaemic control using various treatment regimes will have a significant impact on albumin excretion, morbidity or mortality in NIDDM.

In keeping with previous studies, initial arterial blood pressure was higher in the abnormal groups than in control subjects $[3,5,16,20,22,27]$. The Bedford study [12] found initial systolic blood pressure levels to be higher in subjects who died although significantly predictive only of deaths due to causes other than coronary heart disease. Sasaki et al. [25] showed no difference between observed and expected numbers of deaths related to systolic hypertension. We have not demonstrated an effect of blood pressure on outcome, with similar baseline levels in those who died and survivors, and in those who died of vascular or other causes. These findings cannot be explained by disparate proportions receiving antihypertensive treatment although information regarding the initial use of different classes of anti-hypertensive agent was not available and may be of relevance. The possibility of a type 2 error does exist, as our cohort is smaller than some of these earlier studies.

We have not assessed lipid abnormalities or smoking, in association with raised AER, as possible predictors of excess vascular mortality in this study. Raised cholesterol and triglyceride levels have been shown to be independent predictors of all cause mortality in NIDDM [4] and triglyceride levels predictive of death due to vascular causes [28]. Prospective studies have given conflicting results on the impact of smoking on excess mortality risk $[12,20,28]$.

In conclusion, the demonstrated risk of premature cardiovascular mortality associated with rising AER may be continuous, increasing as the AER rises from normal to abnormal. The risk is well established by the time the AER is in the range of our "Borderline group", i. e. 10.6-29.9 $\mu \mathrm{g} / \mathrm{min}$. Abnormal albumin excretion is associated with increased pre-existing vascular disease and with an excess of deaths due to vascular causes. The presence of large vessel disease per se is a significant predictor of outcome. Prospective studies to assess the effect of intervention on mortality risk in NIDDM are needed to determine how best to prolong life expectancy. In the meantime it seems reasonable to identify those patients with abnormal albumin excretion and/or vascular disease in order to minimise known atherothrombotic risk factors.

\section{References}

1. Mogensen CE (1984) Microalbuminuria predicts clinical proteinuria and early mortality in maturity-onset diabetes. N Eng J Med 310: 356-360 
2. Jarrett RJ, Viberti GC, Argyropoulos A, Hill RD, Mahmud U, Murrells TJ (1984) Microalbuminuria predicts mortality in non-insulin dependent diabetes. Diabet Med 1: 17-19

3. Schmitz A, Vaeth M (1988) Microalbuminuria: a major risk factor in non-insulin dependent diabetes. A 10-year followup of 503 patients. Diabet Med 5: 126-134

4. Mattock MB, Morrish NJ, Viberti GC, Keen H, Fitzgerald AP, Jackson G (1992) Prospective study of microalbuminuria as predictor of mortality in NIDDM. Diabetes 41: 736-741

5. Neil A, Hawkins M, Potok M, Thorogood M, Cohen D, Mann J (1993) A prospective, population-based study of microalbuminuria as a predictor of mortality in NIDDM. Diabetes Care 16: 994-1003

6. Mogensen CE, Chachati A, Christensen CK et al. (1986) Microalbuminuria: an early marker of renal involvement in diabetes. Uraemia Invest 9: 85-95

7. Damsgaard EM, Froland A, Jorgensen OD, Mogensen CE (1990) Microalbuminuria as a predictor of increased mortality in elderly people. BMJ 300: 297-300

8. Yudkin JS, Forrest RD, Jackson CA (1988) Microalbuminuria as predictor of vascular disease in non-diabetic subjects: Islington Diabetes Survey. Lancet II: $530-533$

9. Fabre F, Balant LP, Dayer PG, Fox HM, Vernet AT (1982) The kidney in maturity onset diabetes: a clinical study of 510 patients. Kidney Int 21: 730-738

10. Shenfield GM, Elton RA, Bhalla IP, Duncan LSP (1979) Diabetic mortality in Edinburgh. Diabete Metab 5: 149158

11. Reunanen A (1983) Mortality in type 2 diabetes. Ann Clin Res 15 [Suppl 37]: 26-28

12. Jarrett RJ, McCartney P, Keen H (1992) The Bedford survey: 10 year mortality rates in newly diagnosed diabetics, borderline diabetics and normoglycaemic controls and risk indices for coronary heart disease in borderline diabetics. Diabetologia 22: 79-84

13. Fuller JH, Elford J, Goldblatt P, Adelstein AM (1983) Diabetes mortality: new light on an underestimated public health problem. Diabetologia 24: 336-341

14. Panzram G, Zabel-Langhennig R (1981) Prognosis of diabetes mellitus in a geographically defined population. Diabetologia 20: 587-591

15. WHO Expert Committee on Diabetes Mellitus. Second report. (1980) Geneva, World Health Organization. WHO Technical Report Series 646: 8-12

16. Marshall SM, Alberti KGMM (1989) Comparison of the prevalence and associated features of abnormal albumin excretion in insulin-dependent and non-insulin dependent diabetes. Q J Med 70 (261): 61-71

17. Christensen C, Orskov C (1984) Rapid screening PEG radioimmunoassay for quantification of pathological microalbuminuria. Diabetic Nephropathy 3: 92-97

18. Hirsch RP, Riegelmen RK (1992) Nominal independent variables. In: Hirsch RP, Riegelmen RK (eds) Statistical first aid: interpretation of health research data. Blackwell Scientific Publications, Boston pp 193-194

19. Norusis MJ (1986) SPSS/PC + : SPSS for the IBM PC/XT/ AT. SPSS inc., Chicago

20. Stiegler H, Standl E, Schulz K, Roth R, Lehmecher W (1992) Morbidity, mortality and albuminuria in type 2 diabetic patients: a three-year prospective study of a random cohort in general practice. Diabet Med 9: 646-653

21. Mattock MB, Keen H, Viberti GC et al. (1988) Coronary heart disease and urinary albumin excretion rate in type 2 (non-insulin-dependent) diabetic patients. Diabetologia 31: 82-87

22. Gall M-A, Rossing P, Skott P et al. (1991) Prevalence of micro- and macroalbuminuria, arterial hypertension, retinopathy and large vessel disease in European type 2 (non-insulin-dependent) diabetic patients. Diabetologia 34: 655661

23. Kannel WB, Stampfer MJ, Castelli WP, Verter J (1984) The prognostic significance of proteinuria: the Framingham study. Am Heart J 108: 1347-1352

24. Burden AC, McNally PG, Feehally J, Walls J (1992) Increased incidence of end-stage renal failure secondary to diabetes mellitus in Asian ethnic groups in the United Kingdom. Diabetic Med 9: 641-645

25. Sasaki A, Uehara M, Hasagawa N (1983) A longterm follow-up study of Japanese diabetic patients: mortality and causes of death. Diabetologia 25: 309-312

26. Seivers ML, Nelson RG, Knowler WC, Bennett PH (1992) Impact of NIDDM on mortality and causes of death in Pima Indians. Diabetes Care 15: 1541-1549

27. UK Prospective Diabetes Study (UKPDS) (1993) X. Urinary albumin excretion over 3 years in diet-treated type 2 (non-insulin-dependent) diabetic patients, and association with hypertension, hyperglycaemia and hypertriglyceridaemia. Diabetologia 36: 1021-1029

28. Uusitupa MIJ, Niskanen LK, Siitonen O, Voutilainen E, Pyorala K (1993) Ten-year cardiovascular mortality in relation to risk factors and abnormalities in lipoprotein composition in type 2 (non-insulin-dependent) diabetic and nondiabetic subjects. Diabetologia 36: 1175-1184 